\title{
Transapical mitral valve-in-valve implantation for failed bioprosthetic valve using the J-valve system with locator device: early and mid-term outcomes
}

\author{
Kun Liu ${ }^{1,2}$, Jinglun Shen ${ }^{1}$, Kaisheng Wu ${ }^{1}$, Fei Meng ${ }^{1}$, Shengxun Wang ${ }^{1}$, Shuai Zheng ${ }^{1}$, Haibo Zhang ${ }^{1}$ \\ ${ }^{1}$ Department of Cardiac Surgery, Beijing Anzhen Hospital, Capital Medical University, Beijing, China; ${ }^{2}$ Department of Cardiac Surgery, Cardiac \\ Center of Hennan Provincial People's Hospital, Fuwai Central China Cardiovascular Hospital, Zhengzhou, China \\ Contributions: (I) Conception and design: H Zhang; (II) Administrative support: H Zhang; (III) Provision of study materials or patients: H Zhang, \\ S Wang, S Zheng; (IV) Collection and assembly of data: K Liu, JL Shen, F Meng; (V) Data analysis and interpretation: K Liu, J Shen, K Wu; (VI) \\ Manuscript writing: All authors; (VII) Final approval of manuscript: All authors. \\ Correspondence to: Haibo Zhang, MD. Beijing Anzhen Hospital, Capital Medical University, No. 2 Anzhen Road, Chaoyang District, Beijing 100029, \\ China. Email: zhanghb2318@163.com.
}

Background: Prior to the approval of the Sapien valve in 2020, there were no commercially available short-frame valves for transapical mitral valve-in-valve (MVIV) implantation. In January 2019, we first attempted the reverse mounted J-valve for transapical MVIV implantation with good clinical results. The present study aimed to explore the safety and effectiveness of transapical MVIV implantation with the J-valve reversely mounted on the delivery system.

Methods: Patients who underwent transapical MVIV implantation using the J-valve were analyzed from January 2019 to December 2020 with a 1-year follow-up. Before the procedure, computed tomography (CT) angiography data were analyzed to determine the inner diameter, left ventricular outflow tract (LVOT), and coaxial angel. An oversize rate of 5-10\% was used to select the J-valve depending on the scanned inner diameter of the original mitral bioprosthesis. During the procedure, the three U-shape graspers were one-toone buckled with the three tissue valve struts with the assist of echo and fluoroscopy. The implant depth into the left atrium was a $0-20 \%$ part of the J-valve, and the valve was then released under rapid pacing. Postballoon dilatation was used when needed.

Results: Nineteen patients (mean age $70.05 \pm 11.19$ years), with a mean Society of Thoracic Surgeons score of $8.01 \% \pm 4.20 \%$, were included. By transesophageal echocardiography, we found that the mean transvalvular gradient was $6.21 \pm 2.63 \mathrm{mmHg}$. The mean follow-up time was $20.31 \pm 7.23$ months, and the survival rate was $94.74 \%$ at the last follow-up. The transvalvular gradient decreased from $15.06 \pm 3.00 \mathrm{mmHg}$ at basal to $7.13 \pm 2.28 \mathrm{mmHg}$ at the 1 -year follow-up $(\mathrm{P}<0.001)$. The left ventricular ejection fractions (LVEF) increased from $60.31 \% \pm 7.30 \%$ to $59.94 \% \pm 7.72 \%$ at the 1 -year follow-up $(\mathrm{P}=0.863)$. Thirteen $(81.25 \%)$ patients had no or trace paravalvular leak (PVL), two (12.50\%) patients had minor PVL, one (6.25\%) patient had moderate PVL, and there were no cases of major regurgitation at the 1-year transthoracic echocardiography (TTE) examination results.

Conclusions: The J-valve reversely mounted on the delivery system can be used for transapical MVIV implantation with less operative morbidity and favourable outcomes.

Keywords: Transapical mitral valve replacement; valve-in-valve; bioprosthetic valve deterioration; the J-valve system; 1-year follow-up

Submitted Nov 08, 2021. Accepted for publication Jan 07, 2022.

doi: 10.21037/atm-21-6513

View this article at: https://dx.doi.org/10.21037/atm-21-6513 


\section{Introduction}

The limited service-life of the bioprosthetic valve restricts its widespread application in middle age patients (1). The perioperative mortality of redo open-heart valve replacement surgery makes it difficult for some elderly or high-risk patients to accept the traditional redo open-heart valve replacement surgery under cardiopulmonary bypass (2). In 2007, Grube et al. (3) first applied transcatheter valve-invalve implantation technology to treat bioprosthetic heart valve failure. In several studies, although the Society of Thoracic Surgeons (STS) scores were higher in patients with transcatheter valve-in-valve implantation than redo heart valve surgery, there was no significant difference in the early clinical outcomes and hemodynamic parameters (4-6). The short-term clinical effects of bioprosthetic valves in the aortic position were similar, but differ in the mitral position $(7,8)$. When the bioprosthetic valve failed, the vast majority of mitral valve-in-valve (MVIV) procedures using short frames were Edwards Sapien valves (Edwards Lifesciences, Irvine, CA, USA) $(9,10)$. In 2017, the American Food and Drug Administration approved the MVIV procedure with the Edwards Sapien system (11).

Considering that no short frame valves designed for transapical MVIV implantation have been approved by the China National Medical Products Administration before the Edward Sapien valve in 2020, we speculate that the short frame features and three graspers structure of the J-valve (Jiecheng Medical Technology, Suzhou, China) is suitable for transapical MVIV implantation. The J-valve system is a second-generation self-expandable transcatheter heart valve (THV) through the apical route. The three U-shape graspers are one-to-one buckled with the three tissue valve struts to avoid J-valve displacement to the left atrium (Figure 1). Ye et al. (12) first used the J-valve system for transapical aortic valve-in-valve treatment. In 2019, our center first applied the J-valve reversely mounted on the delivery system for transapical MVIV surgery. The data of patients who underwent transapical MVIV implantation from January to November 2019 were summarized and followed up to analyze the characteristics of the J-valve system in the transapical MVIV implantation.

We present the following article in accordance with the STROBE reporting checklist (available at https://dx.doi. org/10.21037/atm-21-6513).

\section{Methods}

\section{Patients}

All patients were preoperatively assessed independently by at least two cardiac surgeons. The mitral valve replacement algorithm of the STS score system was used to select highrisk patients who required redo mitral valve replacement. All patients in this study provided informed consent prior to undergoing the procedures. The study was conducted in accordance with the Declaration of Helsinki (as revised in 2013), and the study design was approved by the Ethics Review Committee of Beijing Anzhen Hospital (No. 2020079X). All patients underwent transthoracic echocardiography (TTE) to determine the functions of bioprosthesis and other native valves. If the aortic valve had valve stenosis and/or regurgitation, transapical aortic valve implantation was performed.

The bioprosthesis annulus diameter, stent height, mitral valve-aortic valve angle, and mitral valve-apex angle were determined by multi-detector computed tomography (MDCT). The positions of three bioprosthesis struts posts in the left ventricle were primarily determined according to MDCT. It was necessary to make clear the brand and model of the failed bioprosthetic valve through the manufacturer's data. In this way, the inner diameters of the failed bioprosthetic valves could be determined by the manufacturer's data and MDCT to choose the suitable sizes of THVs, with an oversize rate of 5-10\%. Computed tomography (CT) or coronary angiography should be performed for routine preoperative examination of the coronary artery.

\section{Procedure details}

The procedure was performed in the hybrid operating room. The patient was placed supine position and received tracheal intubation under general anesthesia. The apex of the left ventricle was determined by $\mathrm{C}$-arm fluoroscopy and exposed through a small anterolateral thoracotomy. Two pledged purse-string sutures were placed in the apex myocardium of the heart. After the apical puncture, a soft guide-wire and then a super stiff guide-wire were used to cross the bioprosthetic valve and into the left ventricle. The J-valve was reversely loaded on the conveyor system 


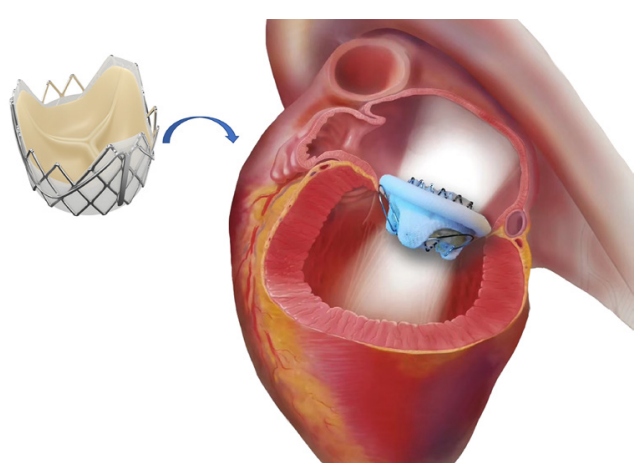

Figure 1 Transapical MVIV implantation with the J-valve. The J-valve has three low frame areas in the middle of the struts posts, which enlarges the outflow area of THV and reduces the probability of left ventricular outflow tract obstruction. The three U-shaped graspers allow the three failed bioprosthetic valve leaflets to be fixed in the middle of shaped graspers and THV frame to avoid THV displacement. MVIV, mitral valve-in-valve; THV, transcatheter heart valve.

and placed along the stiff guide-wire into the left ventricle towards into the left atrium (Figure 2A). The conveyor sheath can be bent at certain angel, which helpful for coaxial implantation. The three U-shaped graspers were first released and were then one-to-one buckled with the three tissue valve struts (Figure 2B).

The J-valve was adjusted to the appropriate depth into the left atrium (usually 10-20\%) and then released (Figure 2C,2D). If the struts post of surgical valves were not clearly visible on fluoroscopy, the released three U-shaped graspers of the J-valve could rotate just at the struts level. When encountering resistance, it could be considered as buckle with the three struts posts. When the depth of the $\mathrm{J}$-valve was too shallow into the left atrium, the rotation would not encounter obvious resistance, and the valve could be further transported into the left atrium.

Due to the longer size, it was difficult for the released U-shaped graspers were to enter the left atrium. Reballoon valvuloplasty of the J-valve was usually needed after the THV release under rapid pacing. The valve position, depth, flow rate, transvalvular pressure, and paravalvular leak (PVL) were determined by transesophageal echocardiography (TEE) and fluoroscopy. Transapical aortic valve implantation can be performed simultaneously. The balloon aortic valve fracture technique (by a powerful non-compliance balloon, Bard Atlas Gold Balloon) was used to enlarge the orifice area, and a bigger size valve was implanted if the original bioprosthetic valve size was less than $21 \mathrm{~mm}$.

\section{Follow-up}

Patients took warfarin after surgery and kept the international normalized ratio between 2.0 and 2.5 for 3 months, and then changed to aspirin for thereafter for life. Patients with contraindications to warfarin or with coronary heart disease used double antiplatelet drugs for 3 months and then changed to aspirin alone. Patients were discharged after evaluation by TTE and electrocardiogram, and accepted TTE and electrocardiography 1-year after discharge from the hospital. The 1-year outcomes were determined by telephone, outpatient service, and follow-up system.

\section{Statistical analysis}

The outcomes were reported according to the Mitral Valve Academic Research Consortium (MVARC) definitions (13). All continuous variables were expressed as the mean \pm standard deviation and tested using the paired student $t$-test. Categorical variables were described by frequencies and percentages. We defined the surveillance period as the time between discharge from the hospital and the last clinical follow-up with the patient. SPSS 26.0 (IBM, Armonk, NY, USA) was used for statistical analysis. $\mathrm{P}<0.05$ was considered statistically significant.

\section{Results}

\section{Baseline characteristics}

From January 2019 to December 2020, 19 patients successfully received transapical MVIV implantation in our center (Beijing Anzhen Hospital, Capital Medical University, Beijing, China). The patients' baseline characteristics are listed in Table 1. The mean age of patients was $70.05 \pm 11.19$ years and $63.16 \%$ (12 cases) were female. Their cardiac functions were New York Heart Association (NYHA) functional class III (84.21\%) or IV (5.26\%), and the mean STS score was $8.01 \% \pm 4.20 \%$.

\section{Valve characteristics}

The mean implant duration of the failed bioprosthetic mitral valves was $11.05 \pm 2.84$ years (from 5 to 15 years). 

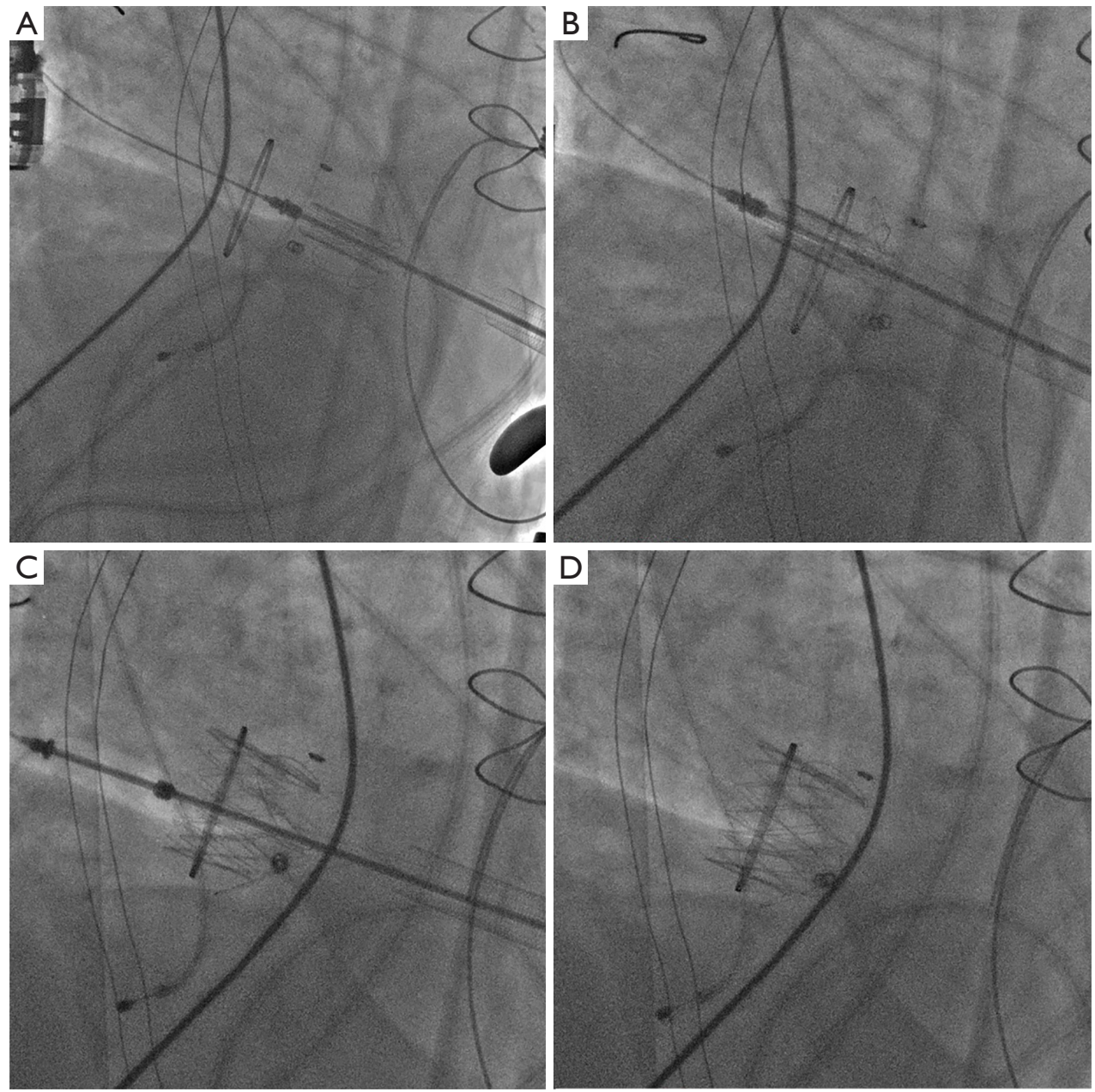

Figure 2 Step-by-step transapical MVIV implantation using the J-valve. (A) The J-valve entered the left ventricle. (B) The three U-shaped graspers were buckled with the three struts posts of the failed bioprosthetic valve. (C) The J-valve was adjusted to the appropriate depth and then released. (D) The J-valve function was good without displacement. MVIV, mitral valve-in-valve.

Among the failed bioprosthetic mitral valves, porcine and bovine pericardial valves were found in $84.21 \%$ (16 cases) and $15.79 \%$ (three cases) of these patients, including $25 \mathrm{~mm}$ in five cases, $27 \mathrm{~mm}$ in 10 cases, and $29 \mathrm{~mm}$ in three cases, respectively. The primary mechanisms of bioprosthetic failure were valve stenosis in four $(21.05 \%)$ patients, valve regurgitation in $12(63.16 \%)$ patients, and combined in three $(15.79 \%)$ patients. The THV size included $23 \mathrm{~mm} \mathrm{~J}$-valve in seven patients (36.84\%), $25 \mathrm{~mm} \mathrm{~J}$-valve in 10 patients (52.63\%), and $27 \mathrm{~mm} \mathrm{~J}$-valve in two patients (10.53\%) (Table 2). Two patients required transcatheter aortic valve replacements, and two patients needed transcatheter aortic valve-in-valve replacements at the same time.

\section{Early outcomes}

The early clinical results are shown in Table 3. All 19 patients were successfully implanted without left ventricular outflow tract obstruction or embolism. Through TEE, we observed that the mean transvalvular gradient was $6.21 \pm 2.63 \mathrm{mmHg}$ during the surgery. No auxiliary circulation support was required postoperatively. One patient received second thoracotomy for bleeding exploration. The mean intensive care unit (ICU) time was $43.05 \pm 46.36$ hours. There were no patient readmissions for 30 days. No new permanent pacemaker, myocardial infarction, stroke, vascular complications, or acute kidney injury were found in these patients. 
Table 1 Demographics and characteristics

\begin{tabular}{lc}
\hline Demographics and characteristics & Values \\
\hline Age, years & $70.05 \pm 11.19$ \\
Female & $12(63.16)$ \\
Height, cm & $162 \pm 6.19$ \\
Weight, kg & $57.26 \pm 10.5$ \\
Hypertension & $8(42.1)$ \\
Diabetes mellitus & $3(15.79)$ \\
Stroke & $1(5.26)$ \\
Chronic kidney disease & $5(26.31)$ \\
Atrial fibrillation & $11(57.89)$ \\
Previous CABG & $4(21.05)$ \\
Prior pacemaker & $3(15.79)$ \\
NYHA class II & $2(10.52)$ \\
NYHA class III & $16(84.21)$ \\
NYHA class IV & $1(5.26)$ \\
Etiology of bioprosthetic valve failure & $11.05 \pm 2.84$ \\
Regurgitation & \\
Stenosis & $12(63.16)$ \\
Mixed & $4(21.05)$ \\
Time since surgical valve, years & $3(15.79)$ \\
Preoperative echocardiography & $6.11 \pm 6.90$ \\
Valtral valve area, cm & \\
STentricular ejection fraction, $\%$ & $C A B G .20$ \\
\hline
\end{tabular}

Values are $\mathrm{n}(\%)$ or mean \pm standard deviation. CABG, coronary artery bypass graft surgery; NYHA, New York Heart Association; STS, The Society of Thoracic Surgeons.

\section{Last follow-up}

The mean follow-up time was $20.31 \pm 7.23$ months. One patient died 3 months after surgery and the survival rate was $94.74 \%$ at the last follow-up. One patient developed upper gastrointestinal hemorrhage 9 months after surgery. One patient had fundus hemorrhage 12 months after surgery. One patient suffered a stroke 10 months after surgery. The patients' heart function also improved, with a decrease in the NYHA class III/IV percentage from $94.44 \%$ to $11.11 \%$ $(\mathrm{P}<0.001$, Figure $3 A)$. No valve-related thrombus or frame expansion was observed in the patients.

\section{Echocardiography results}

Sixteen patients underwent TTE examination 1-year after discharge from the hospital. No THV regurgitation was observed. The transvalvular gradient was decreased from $15.06 \pm 3.00 \mathrm{mmHg}$ at basal to $7.13 \pm 2.28 \mathrm{mmHg}$ at 1-year follow-up $(\mathrm{P}<0.001$, Figure $3 B)$. The left ventricular ejection fractions (LVEF) increased from $60.31 \% \pm 7.30 \%$ to $59.94 \% \pm 7.72 \%$ at the 1 -year follow-up $(\mathrm{P}=0.863)$. Thirteen $(81.25 \%)$ patients had no or trace PVL, two $(12.5 \%)$ patients had minor PVL, one (6.25\%) patient had moderate PVL, with no cases of major regurgitation at 1-year TTE examination results (Figure 3C). The moderate or severe tricuspid regurgitation percentage decreased from $75.0 \%$ to $37.5 \%(\mathrm{P}<0.001$, Figure 3D).

\section{Discussion}

The J-valve is a uniquely-designed valve with three U-shaped graspers surrounding the THV frame. Unlike the positioning keys of other THVs, the three U-shaped graspers of the J-valve are connected to the THV through sutures so that the THV can move along the long axis of the U-shaped graspers. In the process of transapical aortic valve implantation, the curved part of the three U-shaped graspers extends into the three aortic sinuses easily and helps orientate the valve. After implantation, the aortic valve leaflets can be clamped by the U-shaped graspers and fixed to the surrounding of the THV frame, which is helpful in anchoring the valve and reducing the risk of PVL. The J-valve mainly includes five models: $21,23,25,27$, and $29 \mathrm{~mm}$. At present, the J-valve has shown advantages in the application of non-calcified aortic regurgitation in several clinical studies (14-17). In 2017, the China Food and Drug Administration (CFDA) approved the J-valve system for transcatheter aortic valve implantation with aortic stenosis and/or regurgitation.

The J-valve also has advantages in the field of the transapical valve-in-valve implantation. Its low frame valve is suitable for the transcatheter MVIV implantation, which can reduce the influence on left ventricular structure (Figure 1). Owing to the higher left ventricular pressure relative to left atrial pressure, MVIVs anchored only by radial forces are at risk of displacement (18). The three U-shaped graspers, which are one-to-one buckled with the three tissue valve struts, are helpful to avoid delayed valve migration. The three arc-shape of the inflow part stents are missing, which means that the J-valve stent is not a 
Table 2 Valve characteristics

\begin{tabular}{|c|c|c|c|c|c|c|}
\hline Patient number & Years after MVR & Failing BP type & $\begin{array}{l}\text { Failing mitral BP size } \\
\qquad(\mathrm{mm})\end{array}$ & THV type & $\begin{array}{l}\text { THV mitral size } \\
(\mathrm{mm})\end{array}$ & $\begin{array}{l}\text { MG after surgery by TEE } \\
(\mathrm{mmHg})\end{array}$ \\
\hline 1 & 14 & HAN II & 27 & J-valve & 25 & 5 \\
\hline 3 & 10 & Epic & 27 & J-valve & 23 & 9 \\
\hline 6 & 10 & HAN II & 27 & J-valve & 23 & 5 \\
\hline 7 & 12 & HAN II & 25 & J-valve & 25 & 4 \\
\hline 8 & 12 & HAN II & 27 & J-valve & 25 & 3 \\
\hline 12 & 12 & CE porcine & 25 & J-valve & 25 & 10 \\
\hline 13 & 15 & HAN II & 25 & J-valve & 23 & 6 \\
\hline 14 & 9 & HAN II & 29 & J-valve & 25 & 8 \\
\hline 15 & 14 & HAN II & 31 & J-valve & 27 & 3 \\
\hline 16 & 5 & Epic & 29 & J-valve & 25 & 12 \\
\hline 17 & 12 & CE SAV & 25 & J-valve & 23 & 8 \\
\hline 18 & 14 & Bovine valve & 27 & J-valve & 25 & 6 \\
\hline
\end{tabular}

BP, bioprosthetic valve; CE, Carpentier Edwards; HAN II, Hancock II porcine valve; MVR, mitral valve replacement; THV, transcatheter heart valve; TAVR, transcatheter aortic valve replacement; MG, mean gradient; TEE, transesophageal echocardiography.

completely cylindrical metal stent. This feature, coupled with the three $\mathrm{U}$-shape graspers, reduces the probability of left ventricular outflow tract obstruction (Figure 1). Therefore, the J-valve is unexpectedly feasible for transcatheter valve-in-valve implantation. Our center first applied the J-valve reverse loaded on the delivery system for transapical MVIV surgery in January 2019. Since the first application in our center, no patient was intraoperatively converted to thoracotomy due to valve displacement.

A previous multiple center clinical trial reported on 176 patients undergoing transcatheter MVIV surgery in North American and Europe, with a mean STS score of $9.3 \% \pm 7.0 \%$. These patients had 30 -day and 1 -year allcause mortality rates of $5.7 \%$ and $12.6 \%$, respectively, and the 30-day incidences of stroke and life-threatening or fatal bleeding were both $2.3 \%$ (19). Kamioka et al. (4) reported on 62 patients undergoing MVIV implantation with the
Sapien valves; the 30-day and 1-year all-cause mortality rates were $3.2 \%$ and $11.3 \%$ during a follow-up period of 339 days (range, 30 to 1,291 days). In contrast, the J-valve was shown to be safe and effective for transapical MVIV implantation. During a follow-up of 12 patients (mean follow-up time: $20.31 \pm 7.23$ months), the survival rate was $94.74 \%$, and no incidence of valve displacement, shedding, deflection, or other cardiac events at the last follow-up. Also, postoperative cardiac function improved significantly; 16 patients $(84.21 \%)$ showed cardiac NYHA class I or II, and only two patients showed NYHA class III at the last follow-up.

TTE showed good results 1 year after surgery without THV regurgitation. After 1 year, the transvalvular gradient was decreased from $15.06 \pm 3.00 \mathrm{mmHg}$ at basal to $7.13 \pm 2.28 \mathrm{mmHg}$ at 1 -year TTE results. In several studies of Sapien valves in the MVIV implantations, the trans- 
Table 3 Clinical outcomes

\begin{tabular}{|c|c|}
\hline Endpoint & Values \\
\hline \multicolumn{2}{|l|}{ Early outcomes } \\
\hline ICU time, hours & $43.05 \pm 46.36$ \\
\hline Device success & $19(100.0)$ \\
\hline New pacemaker & $0(0.0)$ \\
\hline Stroke & $0(0.0)$ \\
\hline Myocardial infarction & $0(0.0)$ \\
\hline Vascular complications & $0(0.0)$ \\
\hline Bleeding & $1(8.33)$ \\
\hline Acute kidney injury & $0(0.0)$ \\
\hline Readmission at 30 days & $0(0.0)$ \\
\hline Mortality at 30 days & $0(0.0)$ \\
\hline \multicolumn{2}{|l|}{ Last follow-up } \\
\hline Follow-up time, months & $20.31 \pm 7.23$ \\
\hline Mortality at last follow-up & $1(5.26)$ \\
\hline New pacemaker & $0(0.0)$ \\
\hline Stroke & $1(5.26)$ \\
\hline Myocardial infarction & $0(0.0)$ \\
\hline Vascular complications & $0(0.0)$ \\
\hline Bleeding & $2(10.52)$ \\
\hline Blood transfusion & $1(5.26)$ \\
\hline Acute kidney injury & $0(0.0)$ \\
\hline
\end{tabular}

Values are $\mathrm{n}(\%)$ or mean \pm standard deviation. ICU, intensive care unit.

mitral gradients were $5-10 \mathrm{mmHg}(4,19-21)$. The transmitral gradient in our data seems acceptable or even better than these reports, which indicated that the postdilatation after $\mathrm{J}$-valve implantation is helping to reduce the gradient. The degrees of tricuspid regurgitation were also significantly decreased. There was no significant improvement in the LVEF values of high-risk patients, with the consideration of the proportion of patients with atrial fibrillation being $57.89 \%$ and the mean STS score being $8.01 \% \pm 4.20 \%$.

Due to the complex anatomical structure of the mitral valve, the straight and short delivery distance of the transapical MVIV implantation procedure allowed coaxial alignment of the THV valve within the failed bioprosthetic valve to achieve successful valve implantation more easily (22). In some cases, previous mitral valve surgeries performed through the atrial septum incision increases the difficulty of atrial septal puncture for MVIV. Although a small incision in the left chest wall was required (usually around $4 \mathrm{~cm}$ into the thorax), the safety and success of transapical MVIV implantation were also significantly improved due to the avoidance of cardiopulmonary bypass and the relative shortening of the operation time. Yoon et al. (19) showed that although there were no significant differences in clinical outcomes and surgical success rates between transapical and transseptal approaches at 30 days, patients in the transseptal group required more frequent closure of iatrogenic atrial septal defects than those in the transapical group $(12.2 \%$ vs. $0.0 \% ; \mathrm{P}<0.001)$, resulting in a reduced device success rate $(78.0 \%$ vs. $89.1 \% ; \mathrm{P}=0.02)$. Transcatheter aortic valve replacement is also more easily performed via the transapical approach, which reduces the difficulty of surgery. Besides the success MVIV procedures, there were no outflow obstructions or valve displacements in three patients who underwent interventional aortic valve replacements. In order to ensure good coaxial trajectory, the angle between the mitral bioprosthesis annulus plane and left ventricular long axis can be determined preoperatively by MDCT. Since the transporter sheath can be bent, its pre-shaped by hand makes it easier to align the valve with the mitral plane. During the operation, the super stiff guide wire also can assist with valve alignment, and the three positioning graspers can also help determine the valve position.

Selecting the right size THV valve is crucial. Excessively oversized valves are not desirable, as they can lead to considerable overlap of the leaflets and result in higher transvalvular pressure gradients and flexural formation (23). On the contrary, valves that are too small can cause higher transvalvular pressure gradients and increase the risk of PVL and valve migration $(23,24)$. Based on valve data provided by the manufacturer, it is important to select the appropriate THV valve according to the brand and model of the failed bioprosthetic valve $(22,25)$. However, manufacturer data may differ from those obtained by TTE and CT, possibly due to leaflets calcification and even pannus (26). In this situation, CT measurement data is more precise and should be analyzed carefully before the procedure. The balloon valve fracture technique has been used to enlarge the orifice area and widely applied in the aortic valve-in-valve implantation (27). Due to the larger size of mitral tissue valves relative to aortic valves, only a few case reports have detailed the balloon mitral valve fracture 

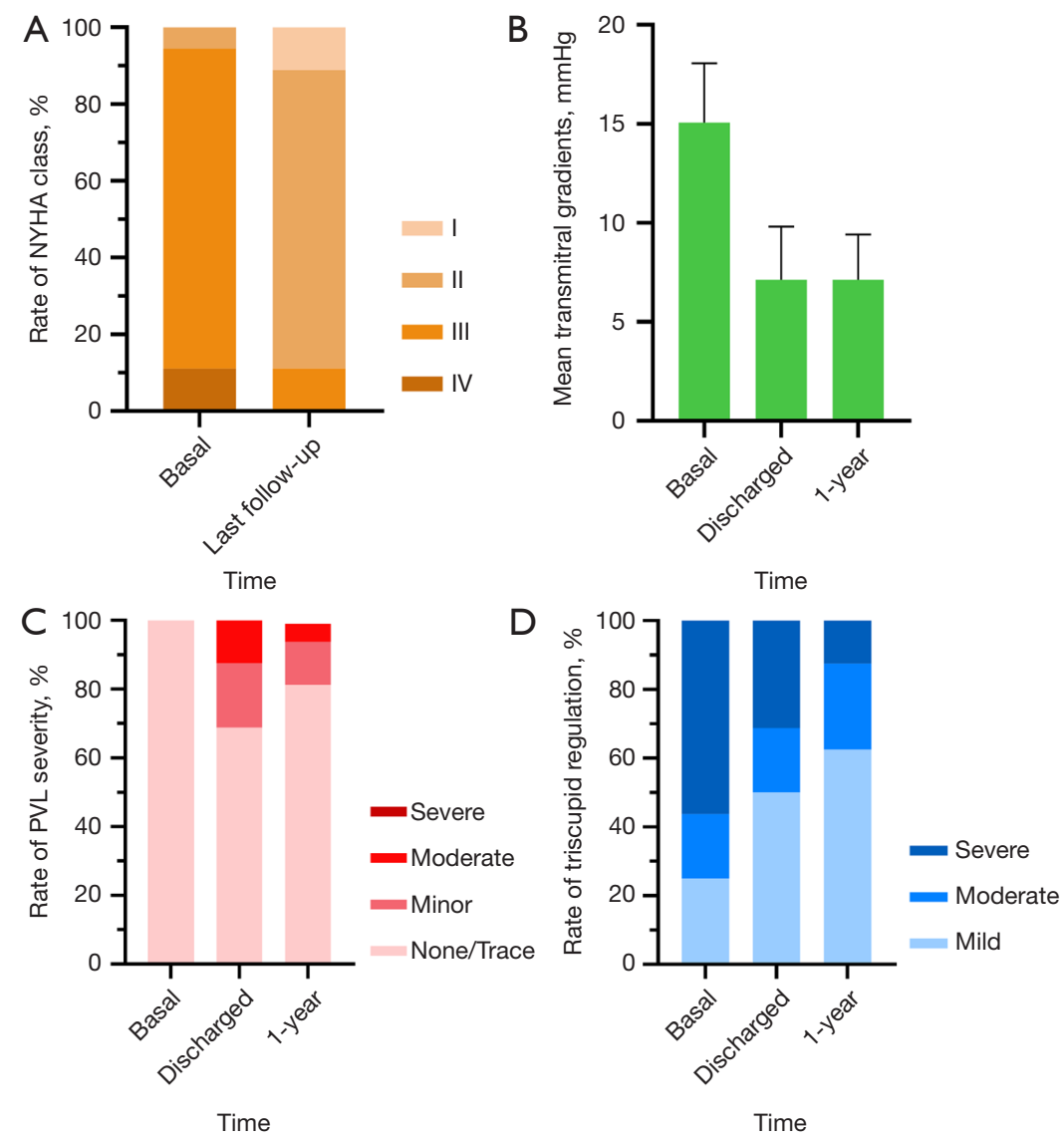

Figure 3 Change in NYHA class and TTE results. (A) The change in NYHA classification (I, II, III, IV) at basal and last follow-up (n=18). (B) The change in transvalvular gradient at basal, discharge, and 1-year follow-up (n=16). (C) The change in paravalvular leak at basal, discharge, and 1-year follow-up ( $n=16)$. (D) The change in tricuspid regurgitation degree at basal, discharge, and 1-year follow-up ( $\mathrm{n}=16$ ). NYHA, New York Heart Association; TTE, transthoracic echocardiography.

technique $(28,29)$, and experience is limited. Considering the risk of left ventricular rupture, coronary artery injury, and annular tear caused by balloon mitral valve fracture, this technique was not used for MVIV implantation. The smallest J-valve for MVIV in our cases was $23 \mathrm{~mm}$. Given the high risk of redo of surgical mitral valves, choosing a 23-mm J-valve for MVIV implantation could also provide benefits, and the average pressure difference was less than $10 \mathrm{mmHg}$ at the 1-year follow-up results.

To select the right size of the intervention valve, we paid attention to the leaflet thickness of the failed bioprosthetic valve, and subtracted the leaflet thickness on the label internal diameter size data given by the manufacturer. Combining the MDCT results, the selected leaflets were appropriate, with an oversize rate of $5-10 \%$. The transvalvular gradient at the 1 -year follow-up was $7.13 \pm 2.28 \mathrm{mmHg}$. Cheung et al. (21) reported on 23 patients using Sapien/Sapien XT valves; three (13\%) THV valves sizes were smaller than the internal diameter size of the failed bioprosthetic valves, with a transvalvular gradient of $6.9 \pm 2.2 \mathrm{mmHg}$. In Elmously et al.'s study (20), no THV valve size smaller than the internal diameter size was selected, and the transvalvular gradient was $5 \pm 3 \mathrm{mmHg}$. Based on the inner diameter of the failed valve and the thickness of the failed valve leaflet, it is meaningful to select the right THV, and the long-term duration of THV needs further follow-up.

PVL seems to be a low probability adverse event. The 1-year TTE results showed that $13(81.25 \%)$ of 16 patients had no or trace PVL, two $(12.5 \%)$ patients had minor PVL, one $(6.25 \%)$ patient had moderate PVL, and there were no cases of major regurgitation. Conradi et al. (30) found three patients with moderate PVL and no patients with severe PVL among 17 cases of transcatheter MVIV implantation with Sapien and Lotus valves (Boston 
Scientific, Marlborough, MA, USA). No PVL was found in Cheung et al. (21) and Elmously et al. (20) studies. Although smaller sized THVs with no excessive oversize was chosen in our cases, the PVL ratio was not obviously increased.

Pre-implantation balloon valvuloplasty was not necessary during surgery, which can lead to acute mitral insufficiency and embolization (21). Cheung et al. (21) and Seiffert et al. (22), reported that no pre-implantation balloon was used in their studies, except for their respective first patients. In our study, pre-implantation balloon valvuloplasty was not used even in patients with bioprosthetic valve stenosis because we are surgeons who are familiar with the tissue valve pathology changes and believe that leaflets with calcium are not difficult to expand. Most THVs require a post-implantation balloon; a post-implantation balloon using a J-valve of the same size can make the interventional and biological valves adhere better, reduce PVL, and lower the transvalvular flow rate and pressure gradient. The self-expanding valves can continuously apply a radial support force on the failed bioprosthetic valves stents, so that the failed leaflets are strongly anchored at the frame. This is also the advantage of the J-valve, with a low frame height and self-expanding frame in transapical valve-in-valve implantation.

Among the failed bioprosthetic valve, the number of porcine valves was more than that of bovine pericardial valves. The present clinical follow-up results proved that the short-term effects of porcine mitral valves and bovine mitral valves were similar, but the use of bovine mitral valves was more effective than that of porcine mitral valves in the long-term effects (31). Bovine pericardial material had stronger mechanical properties than porcine valve and may not be easy to be damaged under the impact of left ventricular blood flow (32).

\section{Conclusions}

The J-valve is a self-expandable valve with three U-shaped graspers. The low frame and three U-shaped graspers were the advantages of the J-valve for MVIV, with a high success rate and fewer complications. The postoperative clinical outcomes and hemodynamic outcomes were satisfactory. The J-valve for MVIV procedure via the apical approach is less difficult to operate and can simultaneously deal with the aortic valve procedure, with satisfactory results. Our innovation in the MVIV with J-valve had expanded to almost 10 centers in China and achieved satisfactory clinical results.
There are some limitations to this study that should be noted. The J-Valve system was not a special interventional valve for MVIV surgery. The lack of design details may be the disadvantage of the MVIV implantation. Since the transapical valve-in-valve implantation has only just begun in China, and the number of patients studied was small, long-term follow-up is needed. Also, as a single center experience, this research is limited by personal techniques and conditions, and cannot provide general technical experience. More data, longer follow-up times, and multicenter studies are needed in the future to evaluate the safety and effectiveness of the J-valve in the field of transapical MVIV implantation.

\section{Acknowledgments}

Funding: This study was funded by the Natural Science Foundation of Beijing Municipality (D171100002917003), the National Key R\&D Program of China (2020YFC2008105) and the Capital Health Research and Development of Special (2020-2-2065).

\section{Footnote}

Reporting Checklist: The authors have completed the STROBE reporting checklist. Available at https://dx.doi. org/10.21037/atm-21-6513

Data Sharing Statement: Available at https://dx.doi. org/10.21037/atm-21-6513

Conflicts of Interest: All authors have completed the ICMJE uniform disclosure form (available at https://dx.doi. org/10.21037/atm-21-6513). The authors have no conflicts of interest to declare.

Ethical Statement: The authors are accountable for all aspects of the work in ensuring that questions related to the accuracy or integrity of any part of the work are appropriately investigated and resolved. All patients in this study provided informed consent prior to undergoing the procedures. The study was conducted in accordance with the Declaration of Helsinki (as revised in 2013), and the study design was approved by the Ethics Review Committee of Beijing Anzhen Hospital (No. 2020079X).

Open Access Statement: This is an Open Access article distributed in accordance with the Creative Commons 
Attribution-NonCommercial-NoDerivs 4.0 International License (CC BY-NC-ND 4.0), which permits the noncommercial replication and distribution of the article with the strict proviso that no changes or edits are made and the original work is properly cited (including links to both the formal publication through the relevant DOI and the license). See: https://creativecommons.org/licenses/by-nc-nd/4.0/.

\section{References}

1. Writing Committee Members; Otto CM, Nishimura RA, et al. 2020 ACC/AHA Guideline for the Management of Patients With Valvular Heart Disease: A Report of the American College of Cardiology/American Heart Association Joint Committee on Clinical Practice Guidelines. J Am Coll Cardiol 2021;77:e25-e197.

2. Jones JM, O'kane H, Gladstone DJ, et al. Repeat heart valve surgery: risk factors for operative mortality. J Thorac Cardiovasc Surg 2001;122:913-8.

3. Grube E, Schuler G, Buellesfeld L, et al. Percutaneous aortic valve replacement for severe aortic stenosis in high-risk patients using the second- and current thirdgeneration self-expanding CoreValve prosthesis: device success and 30-day clinical outcome. J Am Coll Cardiol 2007;50:69-76.

4. Kamioka N, Babaliaros V, Morse MA, et al. Comparison of Clinical and Echocardiographic Outcomes After Surgical Redo Mitral Valve Replacement and Transcatheter Mitral Valve-in-Valve Therapy. JACC Cardiovasc Interv 2018;11:1131-8.

5. Neupane S, Singh H, Lämmer J, et al. Meta-Analysis of Transcatheter Valve-in-Valve Implantation Versus Redo Aortic Valve Surgery for Bioprosthetic Aortic Valve Dysfunction. Am J Cardiol 2018;121:1593-600.

6. Erlebach M, Wottke M, Deutsch MA, et al. Redo aortic valve surgery versus transcatheter valve-in-valve implantation for failing surgical bioprosthetic valves: consecutive patients in a single-center setting. J Thorac Dis 2015;7:1494-500.

7. David TE, Ivanov J, Armstrong S, et al. Late results of heart valve replacement with the Hancock II bioprosthesis. J Thorac Cardiovasc Surg 2001;121:268-77.

8. Poirer NC, Pelletier LC, Pellerin M, et al. 15-year experience with the Carpentier-Edwards pericardial bioprosthesis. Ann Thorac Surg 1998;66:S57-61.

9. Paradis JM, Del Trigo M, Puri R, et al. Transcatheter Valve-in-Valve and Valve-in-Ring for Treating Aortic and Mitral Surgical Prosthetic Dysfunction. J Am Coll Cardiol
2015;66:2019-37.

10. Gurvitch R, Cheung A, Ye J, et al. Transcatheter valve-invalve implantation for failed surgical bioprosthetic valves. J Am Coll Cardiol 2011;58:2196-209.

11. Shivaraju A, Michel J, Frangieh AH, et al. Transcatheter Aortic and Mitral Valve-in-Valve Implantation Using the Edwards Sapien 3 Heart Valve. J Am Heart Assoc 2018;7:e007767.

12. Ye J, Lee AJ, Blanke P, et al. The first transapical transcatheter aortic valve-in-valve implantation using the $\mathrm{J}$-valve system into a failed biophysio aortic prosthesis in a patient with high risk of coronary obstruction. Catheter Cardiovasc Interv 2018;92:1209-14.

13. Stone GW, Vahanian AS, Adams DH, et al. Clinical trial design principles and endpoint definitions for transcatheter mitral valve repair and replacement: part 1: clinical trial design principles: A consensus document from the mitral valve academic research consortium. Eur Heart J 2015;36:1851-77.

14. Wei L, Liu H, Zhu L, et al. A New Transcatheter Aortic Valve Replacement System for Predominant Aortic Regurgitation Implantation of the J-Valve and Early Outcome. JACC Cardiovasc Interv 2015;8:1831-41.

15. Tung M, Wang X, Li F, et al. A versatile transapical device for aortic valvular disease: One-year outcomes of a multicenter study on the J-Valve system. J Cardiol 2018;72:377-84.

16. Li F, Wang X, Wang Y, et al. Structural Valve Deterioration after Transcatheter Aortic Valve Implantation Using J-Valve: A Long-Term Follow-Up. Ann Thorac Cardiovasc Surg 2020;26:158-65.

17. Zhu D, Chen Y, Guo Y, et al. Transapical transcatheter aortic valve implantation using a new second-generation TAVI system - J-Valve ${ }^{\mathrm{TM}}$ for high-risk patients with aortic valve diseases: Initial results with 90-day follow-up. Int J Cardiol 2015;199:155-62.

18. Bapat VV, Khaliel F, Ihleberg L. Delayed migration of Sapien valve following a transcatheter mitral valve-in-valve implantation. Catheter Cardiovasc Interv 2014;83:E150-4.

19. Yoon SH, Whisenant BK, Bleiziffer S, et al. Transcatheter Mitral Valve Replacement for Degenerated Bioprosthetic Valves and Failed Annuloplasty Rings. J Am Coll Cardiol 2017;70:1121-31.

20. Elmously A, Worku B, Gray KD, et al. Mitral Valve-inValve Implantation as an Elective or Rescue Procedure in High-Risk Patients. Ann Thorac Surg 2018;105:1778-83.

21. Cheung A, Webb JG, Barbanti M, et al. 5-year experience with transcatheter transapical mitral valve-in-valve 
implantation for bioprosthetic valve dysfunction. J Am Coll Cardiol 2013;61:1759-66.

22. Seiffert M, Conradi L, Baldus S, et al. Transcatheter mitral valve-in-valve implantation in patients with degenerated bioprostheses. JACC Cardiovasc Interv 2012;5:341-9.

23. Feng W, Yang X, Liu Y, et al. An In Vitro Feasibility Study of the Influence of Configurations and Leaflet Thickness on the Hydrodynamics of Deformed Transcatheter Aortic Valve. Artif Organs 2017;41:735-43.

24. Abbasi M, Azadani AN. Leaflet stress and strain distributions following incomplete transcatheter aortic valve expansion. J Biomech 2015;48:3663-71.

25. Wilbring M, Alexiou K, Tugtekin SM, et al. Transapical transcatheter valve-in-valve implantation for deteriorated mitral valve bioprostheses. Ann Thorac Surg 2013;95:111-7.

26. Wilbring M, Alexiou K, Tugtekin SM, et al. Pushing the limits-further evolutions of transcatheter valve procedures in the mitral position, including valve-in-valve, valve-inring, and valve-in-native-ring. J Thorac Cardiovasc Surg 2014;147:210-9.

27. Saxon JT, Allen KB, Cohen DJ, et al. Complications of bioprosthetic valve fracture as an adjunct to valve-in-valve

Cite this article as: Liu $\mathrm{K}$, Shen $\mathrm{J}, \mathrm{Wu} \mathrm{K}$, Meng F, Wang S, Zheng S, Zhang H. Transapical mitral valve-in-valve implantation for failed bioprosthetic valve using the J-valve system with locator device: early and mid-term outcomes. Ann Transl Med 2022;10(1):21. doi: 10.21037/atm-21-6513
TAVR. Structural Heart 2019;3:92-9.

28. Kamioka N, Corrigan F, Iturbe JM, et al. Mitral Bioprosthetic Valve Fracture: Bailout Procedure for Undersized Bioprosthesis During Mitral Valve-inValve Procedure With Paravalvular Leak Closure. JACC Cardiovasc Interv 2018;11:e21-2.

29. Kaneko T, Piccirillo B, Golwala H, et al. Balloon Fracture of a Surgical Mitral Bioprosthesis During Valve-in-Valve Transcatheter Mitral Valve Replacement: First-in-Human Report. Circ Cardiovasc Interv 2018;11:e006273.

30. Conradi L, Silaschi M, Seiffert M, et al. Transcatheter valve-in-valve therapy using 6 different devices in 4 anatomic positions: Clinical outcomes and technical considerations. J Thorac Cardiovasc Surg 2015;150:155765, 1567.e1-3; discussion 1565-7.

31. Grunkemeier GL, Furnary AP, Wu Y, et al. Durability of pericardial versus porcine bioprosthetic heart valves. J Thorac Cardiovasc Surg 2012;144:1381-6.

32. Soares JS, Feaver KR, Zhang W, et al. Biomechanical Behavior of Bioprosthetic Heart Valve Heterograft Tissues: Characterization, Simulation, and Performance. Cardiovasc Eng Technol 2016;7:309-51. 